\title{
GCU
}

Glasgow Caledonian

University

University for the Common Good

\section{A randomised controlled trial of pelvic floor muscle training for stage I and II pelvic organ prolapse}

Hagen, Suzanne; Stark, Diane; Glazener, Cathryn; Sinclair, Lesley; Ramsay, lan

Published in:

International Urogynecology Journal

DOI:

$10.1007 / \mathrm{s} 00192-008-0726-4$

Publication date:

2009

Document Version

Author accepted manuscript

Link to publication in ResearchOnline

Citation for published version (Harvard):

Hagen, S, Stark, D, Glazener, C, Sinclair, L \& Ramsay, I 2009, 'A randomised controlled trial of pelvic floor muscle training for stage I and II pelvic organ prolapse', International Urogynecology Journal, vol. 20, no. 1, pp. 45-51. https://doi.org/10.1007/s00192-008-0726-4

\section{General rights}

Copyright and moral rights for the publications made accessible in the public portal are retained by the authors and/or other copyright owners and it is a condition of accessing publications that users recognise and abide by the legal requirements associated with these rights.

Take down policy

If you believe that this document breaches copyright please view our takedown policy at https://edshare.gcu.ac.uk/id/eprint/5179 for details of how to contact us. 


\section{Title page}

Title A randomized controlled trial of pelvic floor muscle training for stage I and II pelvic organ prolapse

\section{Author Details}

Name and contact details for corresponding author

Dr Hagen, Suzanne

\section{Statistician and Research Programme Leader}

Urogenital Disorders

Nursing, Midwifery and Allied Health Professions Research Unit

Glasgow Caledonian University

Cowcaddens Road

Glasgow G4 0BA

Telephone: $01413318104 \quad$ E-mail: s.hagen@gcal.ac.uk

Fax: 01413318101

Name and institutional affiliation for other authors

Diane Stark, Clinical Specialist Physiotherapist, Southern General Hospital, Glasgow

Cathryn Glazener, Obstetrician and Senior Clinical Research Fellow, Health Services Research Unit, University of Aberdeen

Lesley Sinclair, Research Fellow, Nursing, Midwifery and Allied Health Professions Research Unit, Glasgow

lan Ramsay, Consultant Obstetrician and Urogynaecologist, Southern General Hospital, Glasgow

\section{Conflicts of interest None}

\section{Funding}

This study was funded by the Chief Scientist Office, Scottish Government $(\mathrm{CZH} / 4 / 95)$. 


\section{Abstract}

\section{Introduction and hypothesis}

Forty-seven women participated in a pilot study for a multi-centre randomized controlled trial of the effectiveness of pelvic floor muscle training (PFMT) for women with prolapse.

\section{Methods}

Women with symptomatic stage I or II prolapse (measured by POP-Q) were randomized to a 16-week physiotherapy intervention (PFMT and lifestyle advice) $(n=23)$ or a control group receiving a lifestyle advice sheet $(n=24)$. Symptom severity and quality of life were measured via postal questionnaires. Blinded POP-Q was performed at baseline and follow-up.

\section{Results}

Intervention women had significantly greater improvement than controls in prolapse symptoms (mean score decrease 3.5 versus $0.1, p=0.021$ ); were significantly more likely to have an improved prolapse stage (45\% vs $0 \%, p=0.038)$ and were significantly more likely to say their prolapse was better (63\% vs $24 \%, p=0.012)$.

\section{Conclusions}

The data support the feasibility of a substantive trial of PFMT for prolapse. A multicentre trial is underway.

\section{Keywords}

pelvic floor muscle training, pelvic organ prolapse, physiotherapy, pilot study, POP-Q

\section{Brief summary}

A pilot trial of pelvic floor muscle training in women with stage I or II prolapse was suggestive of a benefit in terms of improved symptoms and severity. 


\section{Text}

\section{Introduction}

Pelvic organ prolapse (POP), is a common female condition, characterized by symptomatic descent of the vaginal walls, apex or vault from the normal anatomical position [1]. Women with prolapse present with a variety of symptoms (vaginal, urinary, bowel, back, abdominal and sexual). The condition is debilitating and can greatly affect the sufferer's daily activities and quality of life (QoL).

Current treatment options for prolapse include surgery and conservative management. The latter is often considered if the prolapse is small or the patient is not a good candidate for surgery, but can also be used as an adjunct to surgery. Types of conservative intervention include: physical interventions which aim to improve pelvic floor muscle function via pelvic floor muscle training (PFMT); mechanical interventions which aim to manage the prolapse by supporting the pelvic area (e.g. using vaginal pessaries) and lifestyle interventions which seek to avoid exacerbation of the prolapse by decreasing intra-abdominal pressure (e.g. weight loss and avoiding heavy lifting).

Individualised PFMT for women with prolapse is offered by many physiotherapists who specialise in women's health [2]. PFMT would normally involve teaching of pelvic floor exercises, vaginal examination and provision of advice regarding lifestyle changes, and may also include the use of biofeedback, or neuromuscular electrical stimulation. There is evidence that PFMT is effective in the treatment of urinary incontinence [3]. However, clear evidence of the clinical and cost-effectiveness of PFMT in the management of prolapse is lacking. A Cochrane systematic review [4] found only one sizeable trial which included women with prolapse and evaluated a physical intervention. This was a cluster randomized trial of 654 elderly Thai women which focused only on anterior prolapse and did not use a standardised measure of prolapse, but reported significantly less worsening of prolapse in the group receiving pelvic floor exercises and diet/fluid advice [5]. The methodological limitations and restricted population in this trial make interpretation of the findings problematic. The review concluded that, although there is some evidence that pelvic floor exercises may help certain types of prolapse, further evidence from randomized controlled trials of the effectiveness of PFMT for the management of prolapse is required. A further 
study, published more recently, Groubi 2008, conducted a trial in 47 women with stage I or II cystocele. Women were randomized to a treatment group ( $n=27)$ who received PFMT and advice on healthy living or a no treatment group $(n=20)$. Outcomes included clinical examination, the "Measurement of Urinary Handicap" scale, urodynamic tests and patient satisfaction. They reported that immediately post treatment, five women (19\%) in the treatment group still complained of pelvic heaviness, compared with fourteen $(70 \%)$ in the treatment group $(p<0.001)$. Two years after the cessation of treatment 20 women from the intervention group retained benefits.

This paper describes a pilot study for a multi-centre randomized controlled trial of the effectiveness of a PFMT intervention for women with stage I or II pelvic organ prolapse of any type, measured by POP-Q.

\section{Materials and methods}

\section{Recruitment}

Women attending outpatient gynaecology, urogynaecology and prolapse clinics at two Scottish teaching hospitals, with previously untreated prolapse of stage I or II (confirmed by their gynaecologist using the Pelvic Organ Prolapse Quantitation (POP-Q) system [6]), were asked to participate in the trial. Ethical approval was granted in the two centres (Southern General Hospital Ethics Committee; Paper no. EC/02/S/115; approved 25 September 2002 and Grampian Research Ethics Committee; Project no. 02/0243; approved 11 March 2003). For all women, symptoms of prolapse were the main presenting problem. Consenting women were randomized by a remote telephone randomization system to receive individualised PFMT and lifestyle advice or a lifestyle advice leaflet. Trial centre and number of births (none versus one or more) were applied as minimisation criteria.

\section{Intervention group}

The standardised intervention given to women in the PFMT group consisted of five appointments with a specialist women's health physiotherapist over a 16-week period (appointments at weeks 0, 2, 6, 11, 16). At the first appointment, a standardised 
history was taken, and both a subjective prolapse assessment and internal pelvic floor muscle assessment (using the PERFECT scheme, including the modified Oxford scale [7]) were carried out. Anatomy and function of the pelvic floor muscles were taught and types of prolapse described, using diagrams and a model pelvis. Women were also taught how to correctly contract the pelvic floor muscles and how to pre-contract the pelvic floor muscles against increases in intra-abdominal pressure ("the Knack" [8]). An individualised home exercise programme was prescribed and women were encouraged to perform six sets of exercises daily (based on individual muscle assessment, one set consisted of up to 10 maximum voluntary contractions held for up to 10 seconds, with 4 seconds rest between each contraction and $\mathbf{1 0}$ or more fast contractions in a row [7]), with the use of an exercise diary to record compliance. A standardised lifestyle advice sheet was given to women (containing instructions on seeking advice where appropriate about weight loss, constipation, avoidance of heavy lifting, coughing and high impact exercise). Where appropriate, tailored lifestyle advice was also given by the physiotherapist on ways of reducing intra-abdominal pressure to maximise the effects of the PFMT. For example women were advised to change from high to low impact exercise and kneel instead of squat when gardening. Where necessary the physiotherapist negotiated individual circumstances to find solutions to situations which were thought to be causing strain. Symptom changes, compliance with lifestyle advice and changes in pelvic floor muscle strength, assessed by vaginal examination, were recorded at each subsequent 30-minute consultation and the content of the home exercise programme adjusted accordingly.

In order to standardise the physiotherapy intervention, a one-day course was developed and taught by one of the authors (DS) prior to the study starting. Study physiotherapists already had clinical experience in PFMT. The course therefore ensured consistency in: teaching of pelvic floor exercises (PFEs); pelvic floor muscle assessment; lifestyle advice; content of return appointments; use of diaries and standardised leaflets and use of standardised clinical documents to ensure a systematic consultation process.

Control group 
Women in the control group were sent a standardised lifestyle advice sheet immediately after randomization. This leaflet was identical to that given to the intervention women. The control group did not see a physiotherapist, and had no planned contact with the hospital until the follow-up gynaecologist appointment.

\section{Outcome measurement}

Both groups of women completed postal questionnaires (available from the authors) at three time points (baseline i.e. immediately prior to randomization, 20 weeks after randomization, 26 weeks after randomization) and attended a return appointment with their gynaecologist at 20 weeks after randomization.

The outcomes of primary interest were prolapse symptom severity and QoL measured via postal questionnaires [9] and the secondary outcome was prolapse severity (POP-Q) [6] measured by gynaecologists blind to the women's study group allocation. The POP-Q consists of six defined points; two ( $\mathrm{Aa}, \mathrm{Ba})$ on the anterior vaginal wall, two (C,D) at the superior vagina and two (Ap,Bp) on the posterior vaginal wall which are all measured in centimetres with respect to the hymen. In addition, the total vaginal length (with the prolapse reduced) is measured as well as the length of the genital hiatus and perineal body. It is the six internal measurements plus the total vaginal length which are used to calculate the stage of prolapse. In addition, for intervention women only, pelvic floor muscle strength was measured, using the modified Oxford scale [7].

The postal questionnaires included: questions on prolapse symptoms and their impact; the International Consultation on Incontinence Questionnaire (ICIQ) urinary incontinence short form [10]; ICIQ bowel and the vaginal symptoms (an early version) modules [11] and the SF-12 [12]. The core content of the questionnaire remained the same at each time-point. In addition, obstetric history data were gathered in the baseline questionnaire.

\section{Data Analysis}

Analysis of outcome measures was carried out in SPSS version 12 using Chisquare (for women's subjective assessment of change in their prolapse), Fisher's Exact (for POP-Q stage), Mann-Whitney $U$ (for POP-Q individual 
measurements) and Student's unpaired t tests (for prolapse, urinary, bowel and sexual symptoms, prolapse-related QoL and pelvic floor muscle strength) to assess the relationship between group status (intervention/control) and the various outcomes of interest.

\section{Results}

\section{Baseline characteristics}

Forty-seven women were randomized in the 14-month recruitment period from September 2003 to November 2004. The mean age of the group was 56 years (SD 9). All women had experienced at least one vaginal delivery, with the largest group $(40 \%)$ having had 2 deliveries. Fifty-five percent reported all spontaneous vaginal deliveries, and $45 \%$ reported at least one forceps delivery. No caesarean sections were reported. The most common type of prolapse was cystocele (85\%), followed by rectocele (40\%). Forty-seven percent of women had one type of prolapse only, $45 \%$ had two and $8 \%$ had three. The most common combination of prolapse types was cystocele and rectocele (30\%).

There were no significant differences with respect to age, parity, method of delivery, type or duration of prolapse, or prevalence of prolapse symptoms between the intervention and control groups at baseline.

Recruitment, retention and compliance

The response rate to questionnaires sent to women at 20 and 26 weeks (which collected data on the primary outcomes) was $87 \%$ and $85 \%$ respectively, thus drop out from the study was low. Eighty-nine percent of women attended their 20week gynaecology appointment where the follow-up POP-Q assessment was undertaken.

In terms of compliance with intervention, most women in the intervention group $(91 \%)$ attended at least three out of five physiotherapy appointments. Attendance at later appointments was poorer (74\% and 65\% attended for appointments four and five respectively). The average time to complete five appointments was 16 weeks 
(range 15 to 22 weeks). For partial completers, the intervention time ranged from six to 12 weeks. Sixty-one percent of women were rated as good or moderate exercise compliers, based on their exercise diaries and information reported to the physiotherapist.

\section{Prolapse symptoms}

Women were asked how often they experienced various prolapse symptoms, with possible responses being never (0), a little of the time (1), some of the time (2), most of the time (3) and all of the time (4). Prolapse symptoms were widely reported by study women (Table 1). At baseline, the most commonly reported symptom was the feeling of something coming down $(83 \%$ in the intervention group and $75 \%$ in the control group).

A summary index, the Pelvic Organ Prolapse Symptom Score (POP-SS), was formed by summing the seven prolapse symptom responses (article describing the psychometric properties of the POP-SS is in press). There was a significant difference between the intervention and control group in change in POP-SS score from baseline to 26-week follow-up ( $t=-2.298$, $d f=35, p=0.021$ ), indicating that intervention women had significantly greater improvement in symptoms than controls (mean score decrease 3.5 versus $0.1 ; 95 \%$ confidence interval for difference in mean score change $[0.53,6.21])$ (Table 2$)$.

Women were asked to rate on a scale of 0 (not at all) to 10 (a great deal), how much their prolapse symptoms interfered with various aspects of their life (physical activity, social activity, personal hygiene, overall everyday life). There were no significant differences between intervention and control group women in the scores for interference due to prolapse at 20 or 26 weeks.

Women were asked at follow-up how they felt their prolapse was compared to the start of the study. There were significant differences between the intervention and control group at both $20\left(x^{2}=11.465, d f=1, p=0.001\right)$ and 26 weeks $\left(x^{2}=6.320, d f=\right.$ $1, p=0.012$ ), with greater proportions of intervention women reporting their prolapse was better (Table 3). 


\section{Urine, bowel and vaginal symptoms}

Generally there were no significant differences between the intervention and control group in the main urine, bowel or vaginal symptoms at 20 or 26 weeks. For example, change from baseline in the ICIQ urinary incontinence short form scores did not differ significantly between the intervention and control groups (Table 4).

\section{$P O P-Q$ measurements and prolapse severity}

Overall, complete POP-Q data was available for $57 \%$ of examinations. The percentage of women who had the summary POP-Q stage recorded was higher $(91 \%)$, although the stage assigned was not always consistent with the reported POP-Q measurements from which it should have been derived. The POP-Q derived stage was used for analysis purposes.

On five out of 42 occasions the group status of a woman was known to the gynaecologist when performing the follow-up POP-Q assessment. Only three of these ( 1 intervention, 2 control) had associated baseline POP-Q data and therefore contributed data to the analysis; and for all three no change in POP-Q severity was recorded.

Testing the difference between baseline and 20-week POP-Q showed significantly more improvement in the intervention group in the $\mathrm{Aa}$ and $\mathrm{Ba}$ measurements (Mann Whitney $U$ test $z=-2.099, p=0.036$ and $z=-2.677, p=0.007$ respectively) (Table 5).

A test of the difference in POP-Q stage (improved or not improved) from baseline to 20 weeks showed significantly greater improvement in the intervention group (Fisher's exact test $\mathrm{p}=0.038$ ). No control woman had any improvement recorded in her POP-Q severity (Table 6).

Comparison of pelvic floor muscle strength at the first and fifth appointment was conducted ( $n=15$ women attended both these appointments). There was evidence 
of an improvement in muscle strength in the group; mean muscle strength increased by $0.5, \mathrm{SD} 0.6(\mathrm{t}=-3.09, \mathrm{df}=14, \mathrm{p}=0.008,95 \%$ confidence interval $[0.2,0.8])$.

\section{Discussion}

This paper describes a study of the effectiveness of a PFMT intervention for women with pelvic organ prolapse. The data presented here have been used to inform a definitive multi-centre trial to test the hypothesis that PFMT is effective in reducing prolapse symptoms, severity and the need for further treatment.

Questionnaire response rates and follow-up clinic attendance rates in our study were high. Despite the small number of women in the study, data analysis results indicated a positive effect of the intervention on prolapse symptoms and severity.

Prolapse symptoms improved significantly more in the PFMT group, and these women were also more likely to say their prolapse was better at follow-up compared to the start of the study. However, no differences were detected between the groups in terms of how much their prolapse interfered with daily life. This may be due to the specific prolapse symptom questions being more sensitive than those on life interference, and the small sample size. Groubi [?] also found a significant reduction in prolapse symptoms (pelvic heaviness) in a PFMT group compared to no treatment group in a study of $\mathbf{4 7}$ women with stage I or II cystocele.

Because of the lack of trials in this area, no other data have been published for comparison.

A greater improvement in two of the POP-Q measurements ( $\mathrm{Aa}$ and $\mathrm{Ba}$ ) was detected in the intervention group. This suggests that prolapse in the anterior compartment may have improved in the intervention group. Since $85 \%$ of women in the study had a cystocele, improvements might have been expected in this area. Benefits were also found in terms of overall prolapse severity. Only intervention women showed an improvement in their POP-Q stage (5 out of 11 intervention women improved versus 0 out of 9 controls); control women's stage remained either unchanged or worsened. Piya-Anant [5] also reported positive findings from their sizeable trial of pelvic floor exercises plus dietary/fluid advice for anterior prolapse. In 
the group with mild anterior prolapse the rate of prolapse worsening at 12 months was significantly less for intervention women. The rate of worsening of severe anterior prolapse was significantly less in the intervention group than the control after 24 months. Although the study populations are not directly comparable, and the Piya-Anant trial did not use the POP-Q method of assessment, it is interesting that both indicate a benefit from conservative intervention. Similarly, a significant change in prolapse symptoms were seen by Groubi in a study of 47 women with stage I and II cystocele, however again the POP-Q was not used as an outcome measure so a direct comparison cannot be made.

Women in this study who were randomized to PFMT had increased pelvic floor muscle strength by their final appointment. Improvements in pelvic floor muscle strength and coordination are the aims of PFMT. Such muscle changes may improve the support of the pelvic organs and counteract increases in intra-abdominal pressure. There is evidence that PFMT results in increases in pelvic floor muscle strength, and subsequently improvements in symptoms, in women with urinary incontinence [3]. Applying the same principle, improvements in prolapse symptoms might also be expected as a result of PFMT [13]. The PFMT intervention evaluated is based on evidence for prescribing an individual pelvic floor muscle exercise regimen to improve strength, endurance and co-ordination $[7,8]$. This regimen is currently used by UK physiotherapists for conservative management of urinary incontinence [14,15] and prolapse [2]. The intervention duration of 16 weeks was based on the minimum time required for physiological muscle strength changes to occur [15,16]. Exercise regimens were reviewed and progressed following a PERFECT [7] examination at each physiotherapy appointment. The examination includes a method of pelvic floor muscle assessment which has been shown to be reliable in the lying position with bent knees $[7,17]$ as was the standardized position for this study.

In this study pelvic floor muscle strength was measured by the same physiotherapist providing the intervention, thus bias may have been introduced. Pelvic floor muscle strength was not measured in the control group. The rationale for this was the desire to avoid an unintentional training effect in this group, which potentially would have diluted the intervention 
effect. However it is a limitation of the study that conclusions cannot be drawn about how much the change in pelvic floor muscle strength contributes to the positive effect of the intervention as we have no comparison of pelvic floor muscle change between the two groups.

Due to the pilot nature of this study the sample size was small and the duration of follow-up short. The focus was on developing the trial methods and gathering data to inform future sample size calculations.

POP-Q data were often incomplete leading to reduced numbers in the analysis. This is perhaps due to time constraints at clinics, lack of familiarity with the POP-Q and understanding of the importance of this data to the study. Since symptoms and QoL rather than anatomical variables are the primary outcomes in the study the problem of missing POP-Q data is minimized. However the issue does need to be addressed and the provision of thorough training and support for medical staff in using the POP-Q requires consideration in future trials. Successful blinding of gynaecologists during POP-Q assessment was a challenge in this study, and methods for optimizing this process are needed.

This study found a greater improvement in prolapse symptoms in women randomized to PFMT than to control. This study also found that those women randomized to PFMT had an objective improvement in POP-Q measurement compared to no such improvement in those randomized to control. In addition, pelvic floor muscle strength was improved in the intervention group. Due to the small sample size and limited follow-up time further research is necessary to confirm or refute the results. A large multi-centre trial of PFMT, with a minimum of one year follow-up, has now commenced.

\section{Acknowledgements}

Thanks are due to the participants who made the study possible and the staff; in Aberdeen, Chris Bain (Gynaecologist), Lynne Swan (recruitment), Sandra Whyte (intervention physiotherapist), Liz Crothers (intervention physiotherapist); and in Glasgow, Stewart Pringle (Gynaecologist), Sarah Hinks (recruitment), Jackie 
Montgomery (intervention physiotherapist), June McGourty (intervention physiotherapist) and Philippa Dall (data entry). 


\section{References}

1. Abrams P, Cardozo L, Khoury S, Wein A (eds) (2005) Incontinence: 3rd International Consultation on Incontinence, 3rd edn. Health Publications Ltd., Paris.

2. Hagen S, Stark D, Cattermole D (2004) A United Kingdom-wide survey of physiotherapy practice in the treatment of pelvic organ prolapse. Physiotherapy 90(1):19-26.

3. Hay-Smith EJC, Dumoulin C (2006) Pelvic floor muscle training versus no treatment, or inactive control treatments, for urinary incontinence in women. Cochrane Database of Systematic Reviews, Issue 1. Art. No.:CD005654. DOI:10.1002/14651858.CD005654

4. Hagen S, Stark D, Maher C, Adams E. Conservative management of pelvic organ prolapse in women. Cochrane Database of Systematic Reviews 2004, Issue 2. Art. No.: CD003882. DOI: 10.1002/14651858.CD003882.pub3

5. Piya-Anant M, Therasakvichya S, Leelaphatanadit C, Techatrisak K (2003) Integrated health research program for the Thai elderly: Prevalence of genital prolapse and effectiveness of pelvic floor exercise to prevent worsening of genital prolapse in elderly women. Journal of the Medical Association of Thailand 86:509515.

6. Bump R, Anders M, Bo K, Brubaker LP, O'Lancey J, Klarskov P, Shull BL, Smith RB (1996) The standardisation of terminology of female pelvic organ prolapse and pelvic floor dysfunction. American Journal of Obstetrics and Gynecology 175:10-17

7. Laycock J, Jerwood D (2001) Pelvic floor muscle assessment: the PERFECT scheme. Physiotherapy 87(12): 631-642

8. Miller JM, Ashton-Miller JA, DeLancey JOL (1998) A pelvic muscle precontraction can reduce cough-related urine loss in selected women with mild SUI. Journal of the American Geriatrics Society 46(7):870-874

9. Bugge C, Hagen S, Glazener C (2005) The POPPY study: a qualitative evaluation of a pelvic organ prolapse outcome questionnaire. ICS(UK), Glasgow

10. Avery K, Donovan J, and Abrams P (2001) Validation of a new questionnaire for incontinence: the International Consultation on Incontinence Questionnaire (ICI-Q). Neurourology and Urodynamics 20 (4):510-512 
11. Abrams P, Avery K, Gardener N, Donovan J, and on behalf of the ICIQ Advisory Board (2006) The International Consultation on Incontinence modular questionnaire: www.iciq.net. J.Urol. 175:1063-1066

12. Ware JE, Kosinski M, and Keller SD (1996) A 12-Item Short-Form Health Survey: Construction of scales and preliminary tests of reliability and validity. Medical Care, 34(3):220-233.

13. Bo K (2006) Can pelvic floor muscle training prevent and treat pelvic organ prolapse? Acta Obstetrica et Gynecologica 85:263-268

14. Laycock J, Standley A, Crothers E, Naylor D, Garside S, Kiely E, Knight S, Pearson A (2001) Clinical Guidelines for the Physiotherapy Management of Females aged 16-65 with Stress urinary Incontinence. Chartered Society of Physiotherapy, London.

15. National Institute for Health and Clinical Excellence. The management of urinary incontinence in women. London, NICE 2006

16. Bo K (1995) Pelvic floor muscle exercise for the treatment of stress urinary incontinence: An exercise physiology perspective. International Urogynecology Journal 6:282-291

17. Frawley HC, Galea MP, Phillips BA, Sherburn M, Bo K (2006) Reliability of pelvic floor muscle strength assessment using different test positions and tools. Neurourology and urodynamics 25:236-242

Groubi S, Kharrat O, Chaari M, Ben Ayed B, Guermazi M, Elleuch MH (2008) Effect of conservative treatment in the management of low-degree urogenital prolapse. Annales de readaptation et de medicine physique 51: 96-102 


\section{Tables}

Table 1 Prolapse symptoms reported in baseline, 20- and 26-week questionnaires (\% indicating symptom present "a little of the time" or more)

\begin{tabular}{|l|r|r|r|r|r|r|}
\hline & \multicolumn{3}{|c|}{ PFMT } & \multicolumn{2}{|c|}{ Control } \\
\hline Prolapse symptoms & $\begin{array}{r}\text { Baseline } \\
(\mathrm{n}=23)\end{array}$ & $\begin{array}{r}\text { 20week } \\
(\mathrm{n}=19)\end{array}$ & $\begin{array}{r}26 \text { week } \\
(\mathrm{n}=19)\end{array}$ & $\begin{array}{r}\text { Baseline } \\
(\mathrm{n}=24)\end{array}$ & $\begin{array}{r}\text { 20week } \\
(\mathrm{n}=22)\end{array}$ & $\begin{array}{r}26 \text { week } \\
(\mathrm{n}=21)\end{array}$ \\
\hline $\begin{array}{l}\text { Feeling of something coming } \\
\text { down from or in your vagina? }\end{array}$ & 83 & 90 & 63 & 75 & $86 \ddagger$ & 67 \\
\hline $\begin{array}{l}\text { Uncomfortable feeling or pain } \\
\text { in your vagina which is worse } \\
\text { when standing? }\end{array}$ & $73^{\#}$ & 79 & 63 & 63 & 59 & 57 \\
\hline $\begin{array}{l}\text { Heaviness or dragging feeling } \\
\text { in your lower abdomen / } \\
\text { tummy? }\end{array}$ & 61 & $44^{*}$ & 58 & 67 & $62 \ddagger$ & $55 \dagger$ \\
\hline $\begin{array}{l}\text { Heaviness or dragging feeling } \\
\text { in your lower back? }\end{array}$ & 61 & 74 & 53 & 58 & $71 \ddagger$ & 76 \\
\hline $\begin{array}{l}\text { Need to strain (push) to empty } \\
\text { your bladder? }\end{array}$ & $60^{\#}$ & 42 & 53 & 54 & 73 & 67 \\
\hline $\begin{array}{l}\text { Feeling that your bladder has } \\
\text { not emptied completely? }\end{array}$ & 61 & 58 & 53 & 67 & 77 & 71 \\
\hline $\begin{array}{l}\text { Feeling that your bowel has not } \\
\text { emptied completely? }\end{array}$ & 57 & 63 & 53 & 71 & 68 & 57 \\
\hline
\end{tabular}

${ }^{\#} n=22 ;{ }^{*} n=18 ; \dagger n=20 ; \ddagger n=21$, otherwise $n$ for cell is the same as for column 
Table 2 Change in prolapse symptom score*

\begin{tabular}{|l|l|r|r|r|r|}
\hline Change & Group & $\mathrm{n}$ & Mean & SD & $\begin{array}{r}\text { Unpaired } \mathrm{r} \\
\mathrm{p} \text { value }\end{array}$ \\
\hline 20 wks-baseline & PFMT & 17 & -1.94 & 4.8 & 0.080 \\
\hline & Control & 20 & 0.40 & 3.0 & \\
\hline 26 wks-baseline & PFMT & 17 & -3.47 & 5.4 & 0.021 \\
\hline & Control & 20 & -0.10 & 2.9 & \\
\hline
\end{tabular}

*sum of 7 symptom questions, min. $0=$ no symptoms, max. $28=$ all symptoms present all the time

Table 3 Self-reported change in prolapse since start of study (frequency (\%))

\begin{tabular}{|l|r|r|r|r|}
\hline & \multicolumn{2}{|c|}{ PFMT } & \multicolumn{2}{c|}{ Control } \\
\hline & $\begin{array}{r}20 \text {-week } \\
(\mathrm{n}=19)\end{array}$ & $\begin{array}{r}26-\text { week } \\
(\mathrm{n}=19)\end{array}$ & $\begin{array}{r}20 \text {-week } \\
(\mathrm{n}=21)\end{array}$ & $\begin{array}{r}26 \text {-week } \\
(\mathrm{n}=21)\end{array}$ \\
\hline $\begin{array}{l}\text { the same or } \\
\text { worse }\end{array}$ & $9(47)$ & $7(37)$ & $20(95)$ & $16(76)$ \\
\hline better & $10(53)$ & $12(63)$ & $1(5)$ & $5(24)$ \\
\hline
\end{tabular}

Table 4 Change in ICIQ urinary incontinence short-form scores*

\begin{tabular}{|l|l|r|r|r|r|}
\hline & & N & Mean & SD & $\begin{array}{r}\text { Unpaired t } \\
\text { p value }\end{array}$ \\
\hline 20 wks-baseline & PFMT & 19 & -0.21 & 3.2 & 0.494 \\
\hline & Control & 21 & 0.48 & 3.0 & \\
\hline 26 wks-baseline & PFMT & 19 & -1.79 & 3.2 & 0.070 \\
\hline & Control & 20 & 0.00 & 2.8 & \\
\hline
\end{tabular}

${ }^{*}$ min. score 0, max. score 21; higher scores indicate greater leakage and associated bother 
Table 5 Mean difference ${ }^{*}$ (20 weeks - baseline) in measurements for women with complete POP-Q data $(\mathrm{n}=20)$

\begin{tabular}{|r|r|r|}
\hline $\begin{array}{r}\text { Difference in } \\
\text { site } \\
\text { specific points: }\end{array}$ & $\begin{array}{r}\text { PFMT } \\
(\mathrm{n}=11)\end{array}$ & $\begin{array}{r}\text { Control } \\
(\mathrm{n}=9)\end{array}$ \\
\hline $\mathrm{Aa}$ & $-0.36 \mathrm{~cm}$ & $0.67 \mathrm{~cm}$ \\
\hline $\mathrm{Ba}$ & $-1.09 \mathrm{~cm}$ & $0.56 \mathrm{~cm}$ \\
\hline $\mathrm{Ap}$ & $0.18 \mathrm{~cm}$ & $1.44 \mathrm{~cm}$ \\
\hline $\mathrm{Bp}$ & $-0.18 \mathrm{~cm}$ & $1.11 \mathrm{~cm}$ \\
\hline $\mathrm{C}$ & $0.10 \mathrm{~cm}$ & $0.75 \mathrm{~cm}$ \\
\hline $\mathrm{D}$ & $0.20 \mathrm{~cm}$ & $0.75 \mathrm{~cm}$ \\
\hline
\end{tabular}

${ }^{*} \mathrm{~A}$ negative value indicates an improvement at 20 weeks. $\mathrm{n}$ varies as some women had only partial POP-Q data.

Table 6 Change $^{*}$ in severity stage from baseline to 20 -week assessment for women with complete POP-Q data $(n=20)$ (frequency $(\%)$ )

\begin{tabular}{|r|r|r|}
\hline Change in stage & $\begin{array}{r}\text { PFMT } \\
(\mathrm{n}=11)\end{array}$ & $\begin{array}{r}\text { Control } \\
(\mathrm{n}=9)\end{array}$ \\
\hline+2 stages & $0(0)$ & $0(0)$ \\
\hline+1 stages & $1(9)$ & $3(33)$ \\
\hline no change in stage & $5(45)$ & $6(67)$ \\
\hline-1 stage & $4(36)$ & $0(0)$ \\
\hline-2 stage & $1(9)$ & $0(0)$ \\
\hline
\end{tabular}

${ }^{*}$ A negative value indicates an improvement at 20 weeks. 